\title{
The Effect of Information Technology Capability and Quality of Management Accounting Information with Technological Uncertainty as Moderating Variable
}

\author{
Eliada Herwiyanti \\ Faculty of Economics and Busniness, University of Jenderal Soedirman, Jl. Prof HR Bunyamin \\ Purwokerto, Jawa Tengah 53122, Indonesia \\ E-mail: elly_idc@yahoo.com
}

\begin{abstract}
This study aims to determine the effect of information technology capability and quality of management accounting information with technological uncertainty as moderating variable. Data were collected from respondent represented by accounting managers from the companies that listed in Indonesia Stock Exchange. The data processed using Structural Equation Modeling analysis technique. The result of this study support that there is positive effect of information technology capability toward quality of management accounting information. Whereas, technological uncertainty cannot moderates the relationship between information technology capability and quality of management accounting information.
\end{abstract}

Keywords: information technology capability, technological uncertainty, quality of management accounting information

\section{Introduction}

Information quality is a competitive advantage for an organization. Information is one of the business resources, like other resources, information important to the survival of the organization. ${ }^{1}$ Companies that want to survive in a competitive environment require managers to be able to identify and make sense of strategic issues as a prerequisite for strategic change. ${ }^{2}$ The fast industrialization at the end of the nineteen century has made accounting management information an alternative management tool to control the working performance. Accounting management information plays a dominant role in management in the early twentieth century.

Business competition has grown tighter because of uncertainty, obscurity, and fast business environment that rapidly grow. Companies make efforts to reduce the obstacles and get the competitive advantages through investment and implementation of information technology. Therefore, information technology plays a significant role in the social and economic changes.

An organization keeps trying to find opportunities to use technology materials and more advanced information system to obtain more effective strategies. To be able to design and manage the technology structure and information system well, learning processes is required. Organization learning is now becoming an important process to be carried out.

\section{Theoretical Framework}

\subsection{Resource-Based View}

The foundations of the Resource-Based View (RBV) of the company can be found in the works of Penrose in the mid-20th century that adheres to that company as an administrative organization and a collection of productive resources, both physical and human. ${ }^{3}$ Resources can be tangible or intangible. Resources include intangible assets such as reputation, brand image and product quality, while the resource base personnel include engineering know-how, and other knowledge assets, including dimensions such as organizational culture, training of employees, loyalty, etc. Resource companies can be classified into three categories, namely: physical capital resources, human capital resources and organizational capital resources. There are certain conditions that resources should be presented to allow the company to continue its 
competitive advantages, namely: scarcity, value, cannot be imitated, and not replaceable. ${ }^{4}$

RBV company primarily focused on internal company resources and capabilities, to explain the profit and value of the organization. ${ }^{4,5}$ This theory is applied to explain the differences in performance within an industry. ${ }^{6} \mathrm{RBV}$ company states that the difference in performance occurs when successful organizations have available resource that is not owned by other organizations, allow them to get a lease in the form of quasi-monopolists. ${ }^{5}$ Consider a strategic perspective on RBV company, organization is a collection of unique competencies and capabilities that influence its evolution and growth of strategic choice. ${ }^{1,4}$

Resource base view emphasizes the internal capabilities of the organization to achieve a sustainable competitive advantage in the market and industry. Internal capabilities determine organizational strategic options that can be used to compete for external environments. Competition resource base is described as a competition of resources and capabilities that exist within an organization or internal resources and capabilities that will be developed by an organization. Effective configuration of resources and capabilities that exist within an organization will provide competency. Competence is an attribute that is required in order for a company to compete for the market. Competence can be achieved from a collection of resources owned by the company. ${ }^{7}$

Resources were classified following the IT base sequence of three sequences, namely:

(i) Intangible Resources consist of the physical components of the IT infrastructure,

(ii) Human resources consist of ITmanagerial and technical expertise, and

(iii) Resources consist of IT enable dintangibles such as knowledge assets, customer orientation, and synergy.

\subsection{Contingency theory (Lawrence and Lorsch)}

This theory focus on the organizational structure of the dependency on the surrounding environment, the main hypothesis is:

"Those having an internal organization structure that matches the demands from the best surroundings have the best chance to survive."

Lawrence and Lorsch emphasize that organizations should match the surrounding environment at two levels:

- Each organizational unit must be adapted to the environment associated with the organization.

- Differences in the organization as a whole should show the surrounding environment where the organization operates. ${ }^{9}$

The important conclusion of Lawrence and Lorschis is that the most effective organizations have developed coordination and conflict resolution system, which ensures the company is not for the faint of differences and of acute and long-term problems. ${ }^{9}$

\section{Hypothesis Development}

\subsection{Information technology capability and quality of accounting management information}

Information technology (IT) has a strong influence on the way the organization operates. IT enabled organizational structure that will allow the creation of tasks and reporting relationships of new types of employment among people who are connected electronically and supports communication between superiors and subordinates. One type of the relationship that enabled IT organizations that have important implication for organizational learning and knowledge management is the decision-making, sharing and integration of expertise within and between functions and divisions through real-time, i.e., interconnected IT. Knowledge management system was developed to improve the ability of workers and to gain important knowledge that makes them desire to serve customers better. One of the main advantages of the use of knowledge management systems is the development of people and group synergy that can result in a competitive advantage in the form of product or service differentiation. Unlike rigid bureaucratic organization method, which enabled IT organizations can respond quickly to rapidly changing environmental conditions according to the demands of global competition.

Technical ability specifically describes an important potential source of competitive advantage and superior performance in a competitive market technologically. ${ }^{10,11}$ Technology capability help the company's ability to recognize and apply new external knowledge to further the development of competencies, which can result in superior performance. IT capability was found to be an important differentiator of good banks in the mid-1980s, when compared with banks that are less good. ${ }^{12}$

IT resource base view shows that the company is not only able but also to differentiate themselves on the basis of their IT resources. Infrastructure of an enterprise, namely IT human capability, and the ability to improve IT for intangibles benefits provided as a special company resource, which when combined will create vast IT capabilities. When each firm's complex IT resources are difficult to imitate, the company reached a competitive advantage through IT will also learn to 
effectively combine their IT resources to create an overall IT capability. ${ }^{4}$

Previous research on information technology capability has been relatively much done. However, that was built with the Resource-Based View theory of the field of accounting is still relatively small. Bharadwaj and Wang et al. were used as a reference study by Rattanaphaphtham and Ussahawanitchakit which examines the relationship between information technology capabilities to the quality of management accounting information. ${ }^{7,13,14}$ The research results of Rattanaphaphtham and Ussahawanitchakit found no significant effect between the capabilities of information technology on the quality of management accounting information. ${ }^{14}$ Moorthy et al. in the context of human resources examines the importance of the application of information technology in management accounting decisions to find the importance of the role of information technology for the efficiency of the accounting department. ${ }^{15}$

Based on the RBV perspective, the information technology capability is one of the resources that can provide a competitive advantage for the organization. When the competitive advantage of the organization can be put to good firm performance will be better. Taking into account of the importance of IT capability as supporting the creation of quality management accounting information a sit proposed the following hypothesis:

Hypothesis 1: The information technology capability has positive impacts on the quality of accounting management information

\subsection{Technological uncertainty in information technology}

Technological uncertainty is described as the extent of change and predictability in an industry technology development organization. ${ }^{16}$ Organizations that work with new technologies that are changing rapidly will tend to gain a competitive advantage through technological innovation. Thereby, the problem then arises of how to stay abreast of technology trends through improving, strengthening, and improving technological capabilities. So the only company with a strong technological capability, which can create quality information on decision making, achieve high performance and survive in the technological uncertainty. ${ }^{13}$

Accounting information system as one of the most important systems in the organization will change from away of capturing, processing, storing, and distributing information. Nowadays, more and more digital and online information used in accounting information systems. Organizations need to conduct an approach that put the system on the forefront, taking into human factors and systems as well as managing the accounting information system. Failure to implement the accounting information system will have a negative effect on the organization's financial processes. ${ }^{17}$

The company with high technology learning will contribute both to the quality of management accounting information. Technological uncertainty on the one hand can be a limiting factor of the smooth distribution of knowledge to individuals, individuals and companies as a whole, and on the other hand can also be a motivating factor of the willingness of the company to further enhance their resources and ultimately when the resource is in the form of technological capabilities into will both improve the performance of the company.

Research using technology uncertainty variables has been done. But not everything is done in the context of management information systems. Research $\mathrm{Li}$ and Lin conducted in the context of information systems technology management discovered that uncertainty does not affect the quality of the information. ${ }^{16}$ Research Wang et al. conducted in the context of marketing found that technological uncertainty is a positive moderating the relationship to the overall performance capabilities of the technology business. ${ }^{13}$ However, research Rattanaphaphtham and Ussahawanitchakit conducted in the context of accounting shows that the results are not significantly influence technological uncertainty as moderating the relationship between information technology capabilities with quality management accounting information. $^{14}$

Wang et al. Found that the uncertainty of the technology is able to moderate the relationship of the information technology capability and the quality of accounting management information, explained that companies with high technology in an environment of uncertainty would likely able to utilize their technology capability to improve the performance. ${ }^{13}$ Meanwhile, Rattanaphaphtham and Ussahawanitchakit were not able to find technologies uncertainty moderate the relationship of information technology capabilities with the quality of information, explaining that the uncertainty of high technology was not able to spur the company to further enhance its technological capabilities to produce quality information quality. ${ }^{14}$

The success of the performance is not only determined by internal factors, but also can be influenced by external factors. Based on the RBV perspective, information technology capability is one of the resources that can provide a competitive advantage for the organization. Based on Contingency Theory perspective, the organization will be successful if it is 
able to design and connect the appropriate structures and systems. The presence of environmental factors that are full of uncertainty must be addressed to ways that effective corporate performance can be maintained. The uncertainty of the technology will support the company to better utilize its information technology capabilities, thus the relationship between information technology capability and quality of management accounting information will be more closely. Based on the Contingency theory that integrated with RBV theory and still inconsistent results of previous studies related to the moderating role of technological uncertainty variable, then the hypothesis can be put forward as follows:

Hypothesis 2: The high uncertainty rate of technology strengthens the relation between the information technology capability and the quality of accounting management information.

\section{Methodology}

In this study, primary data were collected from the answers of the distributed questionnaires. The research population was 443 go public companies listed in the Indonesian Stock Exchange (www.idx.co.id). Respondents represented by the accounting manager participated in the questionnaire completion.

The analysis used to examine the hypothesis is the structural equation model (SEM). Data were analyzed using the SPSS 16.0 software and WarpPLS 4.0 software. SPSS 16.0 softwarewas used to analyze the data characteristic, meanwhile the WarpPLS 4.0 software was used to analyze the research model of SEM.

In this study, hypothesis testing was carried out using the Partial Least Squares-Structural Equation Modeling (PLS-SEM). This PLS is a powerful analysis method and is often called as soft modeling. PLS can also be used to confirm theories. ${ }^{18}$

\section{Result}

\subsection{Research Variable Description}

Description of variables was presented by statistic description (see Appendix A). Index number and category for each variable determine by Ferdinand's index (see Appendix B). ${ }^{19}$ Profile of 94 research respondent (based on the type of industry sector) was presented in Appendix C. Below is the summary of research variable:
Table 1: Summary of Variable Description

\begin{tabular}{|l|c|c|c|c|}
\hline Variable & $\begin{array}{c}\text { Expectation } \\
\text { Range }\end{array}$ & $\begin{array}{c}\text { Real } \\
\text { Range }\end{array}$ & $\begin{array}{c}\text { Index } \\
\text { Number }\end{array}$ & Category \\
\hline KTI & $10-50$ & $16-44$ & 65.59 & Medium \\
\hline TUN & $4-20$ & $4-18$ & 68.67 & Medium \\
\hline KIAM & $10-50$ & $24-50$ & 75.80 & High \\
\hline
\end{tabular}

Source: analyzed using SPSS 16.0 and Ferdinand's index calculation

$$
\begin{aligned}
& \text { Notes: } \\
& \text { KTI }=\text { information technology capability } \\
& \text { TUN }=\text { technological uncertainty } \\
& \text { KIAM }=\text { quality of management accounting } \\
& \text { information }
\end{aligned}
$$

Output for the research model is as on figure below:

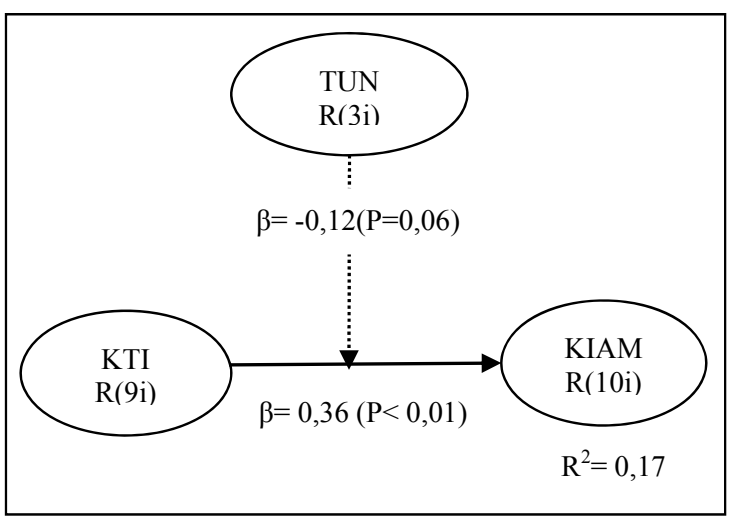

Fig.1 Structural Model (output from Warp PLS 4.0)

$$
\begin{aligned}
& \frac{\text { Notes: }}{\text { KTI }}=\text { information technology capability } \\
& \text { TUN }=\text { technological uncertainty } \\
& \text { KIAM }=\text { quality of management accounting } \\
& \text { information } \\
& \text { R(i) } \quad=\text { number of indicator in the variable }
\end{aligned}
$$

\subsection{Hypothesis 1}

Hypothesis 1 states that information technology capability has positive impacts on the quality of accounting management information. The testing results show that there is estimation coefficient 0.36 with $\mathrm{P}$ value 0.01 (significant on level 0.01). Figure 1 show that there is positive and significant impact from the variable of information technology capability towards the variable of accounting information quality. 
Therefore, with $99 \%$ certainty the hypothesis 1 is accepted.

The testing result of hypothesis stating that information technology capability has positive impact on the quality of accounting management information indicates that the hypothesis is accepted. This means that the quality of accounting management information is influenced by the information technology capability. Table 1 shows that respondents averagely have medium information technology capability and high quality of accounting information. Therefore, it can be concluded that information technology capability has significant impacts towards the quality of accounting management information. This is due to the fact that although the responses are not very high, they bring significant impacts on the quality of accounting management information. The positive and significant testing result on information technology capability on the quality of accounting management information indicates the importance of sufficient resources capability for companies. Information technology capability as one type of the capabilities of companies influences the quality of accounting management information. Information technology capability as pieces of significant knowledge requires more intensive attention to increase the working performance of the company. Companies that succeed in creating qualified information technology capability will certainly enjoy the maximum working capital.

\subsection{Hypothesis 2}

Hypothesis 2 states that high uncertainty level of technology strengthens the relation between information technology capability and quality of accounting management information. The testing results show that there is estimation coefficient -0.12 with $\mathrm{P}$ value 0.24 . Figure 1 shows that there is negative impact but insignificant from the variable of technology uncertainty towards the variable of information technology capability which is moderated by variable of technology uncertainty. It can be concluded that with $25 \%$ certainty, hypothesis 2 is rejected.

The testing results of the hypothesis stating that the high uncertainty of technology will strengthen the relation between the information technology capability towards the quality of accounting management information is denied. This means that high uncertainty of technology does not strengthen the relation between the information technology capabilities towards the quality of accounting management information. This finding shows that technology uncertainty is not appropriate when considered as the relation moderation between the information technology capabilities towards the quality of accounting management information. Table 1 shows that respondents averagely have medium technology uncertainty and high quality of accounting management information. Therefore, technology uncertainty is not able to encourage the information technology capability to become more positively influential towards the quality of accounting management information. Information technology capability and technology uncertainty are two different things. On the one hand, information technology capability is the internal factor. On the other hand, technology uncertainty is the external factor. However, those two factors can be integrated to bring more benefits for companies. The precise action of companies in responding technology uncertainty can optimize information technology they have to generate qualified accounting management information. Therefore, information technology capability and technology uncertainty require more attention and should be positively responded to promote more qualified accounting management information.

\section{Conclusion}

(i) Information technology capability has positive and significant impact on the quality of accounting management information.

(ii) Technology uncertainty as the moderation has negative impact yet not significant towards the quality of accounting management information.

\section{Implication}

(i) The results showed that the capability of information technology affects the quality of management accounting information should be a reference to the Human Resources and Information Technology division to be able to understand what the needs of the company, primarily for the accounting department to support the availability of information quality.

(ii) The results of the moderating role of uncertainty related to the relationship of technology capabilities of information technology with quality management accounting information indicates that the Information Technology and accounting departments should work to get her when faced with the uncertainty of the technology, so that the capabilities of existing information technology in the enterprise can be enhanced to support the creation of information quality of management accounting.

\section{Acknowledgements}

I would like to thank Prof.Mohamad Nasir, PhD., MSi., Ak. And Dr.Agus Purwanto, MSi., Ak.,for their 
willingness to guide during the completion process of this research.

Furthermore I would also like to acknowledge with much appreciation the crucial role of accounting managers of the research sample, who participate in the research. A special thank go to The Chief and staffs of Universitas Jenderal Soedirman for their support until the finishing of this study.

\section{References}

1. Hall, James A, Accounting Information Systems, 3rdedn.(South-Western College Publishing,USA, 2001).

2. Heidmann, Marcus, Utz Schaffer, and Susanne Strahringer, Exploring the Role of Management Accounting Systems in Strategic Sensemaking, Information Systems Management, 25 (2008) 244-257.

3. Penrose, E.T, The Theory of the Growth of the Firm(John Wiley, New York, 1959).

4. Barney, J. B, Firm Resources and Sustained Competitive Advantage, Journal of Management, 17 (1991) 99-120.

5. Wernerfelt, B, A Resource-based View of The Firm, Strategic Management Journal, 24, (1984) 171-180.

6. Hoopes, D, Madsen T, and Walker G, Guess Editor's Introduction to The Special Issue: Why Is There a Resource-based View? Toward A Theory of Competitive Heterogeneity, Strategic Management Journal, 24 (2003) 889-902.

7. Bharadwaj, Anandhi S, A Resource-Based Perspective on Information Technology Capability and Firm Performance: An Empirical Investigation, MIS Quarterly, 24(1) (2000) 169-196.

8. Grant, R.M, Contemporary Strategy Analyis, (Blackwell Publishers Inc, Oxford, UK, 1995).

9. Lawrence, P and J. Lorsch, 1967, Organization and Environment-Managing Differentiation and Integration,(Harvard University, Boston, 1967).

10. Nelson R. and Winter S, An Evolutionary Theory of Economic Change, (Harvard University Press, Cambridge, 1982).

11. Tyler B.B, The Complementarity of Cooperative and Technological Competencies: A Resource-based Perspective, Journal of Engineering and Technology Management, 18(1), (2001) 1-27.

12. Nolan, Richard L, Note on Estimating the Value of the IT Asset, Harvard Business School, 9, (1994)(195-197).

13. Wang, Yonggui, Hing-Po Lo, Quan Zhang, and Youzhi Xue, How Technological Capability Influences Business Performance: An Integrated Framework Based on The Contingency Approach, Journal of Technology Management, 1(1) (2006) 27-52.

14. Rattanaphaphtham, Kanyanat and Phapruke Ussahawanitchakit, The Influence of Learning Orientation and Information Technology Capability in Information Quality of Management Accounting System: A Moderating Effect of Technology
Uncertainty, Review of Business Research, 8(2), (2008) 207-216.

15. Moorthy, Khrisna M, Ong Oi Voon, Cik Azni Suhaily, M. Gopalan, and King-Tak Yew, Application of Information Technology in Management Accounting Decision Making, International Journal of Academic Research in Business and Social Sciences, Vol 2(3) 2012.

16. Li, Suhong and Binshan Lin, Accessing Information Sharing and Information Quality in Supply Chain Management, Decision Support Systems, 42(3)(2006) 1641-1656.

17. Xu, Hongjiang, Data Quality Issues for Accounting Information Systems' Implementation: Systems, Stakeholders, and Organizational Factors, Journal of Technology Research, Data Quality Issues (1)(2009) 111.

18. Kock, Ned, WarpPLS4.0: User Manual,(ScriptWarp Systems, Texas, 2013).

19. Ferdinand, Augusty, Metode Penelitian Manajemen: Pedoman penelitian untuk Penulisan Skripsi, Tesis, dan Disertasi Ilmu Manajemen (BP Undip, Semarang, 2013).

\section{Appendix A. Statistic Description}

\begin{tabular}{|l|r|r|r|}
\hline & KTI & TUN & KIAM \\
\hline Mean & 32.71 & 13.73 & 37.83 \\
\hline Std. Error of Mean & 0.55 & 0.23 & 0.62 \\
\hline Median & 31.00 & 14.00 & 39.00 \\
\hline Std. Deviation & 5.38 & 2,22 & 5.98 \\
\hline Minimum & 16 & 4 & 24 \\
\hline Maximum & 44 & 18 & 50 \\
\hline
\end{tabular}

Source: analyzed using SPSS 16.0

\section{Appendix B. Index Calculation}

Index calculation was done using the Ferdinand's formula ${ }^{19}$ as follows:

$$
\mathrm{NI}=((\% \mathrm{~F} 1 \times 1)+(\% \mathrm{~F} 2 \times 2)+\ldots+(\% \mathrm{Fnxn})) / \mathrm{n}
$$

Notes:

F1= Percentage frequency of respondents who answered the first $\mathrm{n}$ numbers

F2 = Percentage frequency of respondents who answered these second $n$ numbers

$\mathrm{Fn}=$ Percentage frequency of respondents who answered a number to-n

$\mathrm{n}=$ score value 
Appendix C: Research Respondent Profile (based on the type of industry sector)

\begin{tabular}{|l|r|r|}
\hline \multicolumn{1}{|c|}{ Sector } & Amount & Percentage \\
\hline Agriculture & 4 & 4.30 \\
\hline Mining & 8 & 8.50 \\
\hline $\begin{array}{l}\text { Basic Industry and } \\
\text { Chemicals }\end{array}$ & 6 & 6.40 \\
\hline Miscellaneous & 7 & 4.30 \\
\hline $\begin{array}{l}\text { Consumer Goods } \\
\text { Industry }\end{array}$ & 12 & 7.40 \\
\hline $\begin{array}{l}\text { Property, Real Estate and } \\
\text { Building Construction }\end{array}$ & 7 & 7.40 \\
\hline $\begin{array}{l}\text { Infrastructure, Utilities, } \\
\text { and Transportation }\end{array}$ & 24 & 25.50 \\
\hline Finance & 22 & 23.40 \\
\hline $\begin{array}{l}\text { Trade, Service and } \\
\text { Investment }\end{array}$ & \multicolumn{2}{|c|}{ Total } \\
\hline
\end{tabular}

Source: analyzed using SPSS 16.0 